\title{
Incidence of postsurgical pulmonary embolism and deep venous thrombosis: a single-center retrospective observational study
}

\author{
Hitomi Otsuka*, Makoto Izumi, Eriko Ota and Noriaki Mochizuki
}

\begin{abstract}
Background: Cancer is a risk factor for perioperative deep venous thrombosis and pulmonary embolism (DVT/PE). However, there is a paucity of data on non-malignant digestive diseases. In this study, we aimed to investigate the incidence of DVT/PE among patients, following surgery for acute appendicitis and other digestive diseases.

Methods: We retrospectively reviewed the records of patients who underwent surgical procedures involving the digestive system between April 2018 and March 2019 attended by anesthesiologists $(n=536)$.

Results: DVT/PE developed in seven patients (7/77, 9.1\%, 95\% confidence interval [Cl] 3.7-17.8\%) after surgery for acute appendicitis, and in six patients $(6 / 83,7.2 \%, 95 \% \mathrm{Cl} 2.7-15.1 \%)$ after elective surgery for colorectal cancer. Among the acute appendicitis group, six patients (6/30 20.0\%) with complicated appendicitis (gangrenous or perforated appendicitis), and one patient (1/47 2.1\%) with simple appendicitis showed postoperative DVT/PE. Patients with complicated appendicitis had a higher risk of DVT/PE than those with simple appendicitis with an odds ratio of $11.5(95 \% \mathrm{Cl} 1.3-101.1)$.

Conclusions: Although patients with acute appendicitis lack three of the risk factors for DVT/PE (cancer, long operative time, and older age), their $95 \% \mathrm{Cl}$ for the incidence of DVT/PE was comparable to that of patients undergoing elective surgery for colorectal cancer. Therefore, caution must be exercised during the perioperative period for preventing DVT/PE.
\end{abstract}

Keywords: Deep venous thrombosis and pulmonary embolism, Acute appendicitis, Complicated appendicitis, Ddimer, Enhanced computed tomography scan

\section{Introduction}

Deep venous thrombosis and pulmonary embolism (DVT/PE) could lead to life-threatening events during the perioperative period. It is well known that cancer patients are at a high risk of DVT/PE [1], because the tissue factor activates the coagulation pathway. There are several studies on the incidence of DVT/PE among cancer patients $[2,3]$. However, there is a paucity of date

\footnotetext{
* Correspondence: hto.otsuka@gmail.com

Department of Anesthesiology, Shinshu Ueda Medical Center, 1-27-21, Midorigaoka, Ueda City, Nagano 386-8610, Japan
}

regarding non-malignant digestive diseases as risk factors for DVT/PE.

We encountered seven cases of DVT/PE after appendectomy in our center last year. $\mathrm{Li}$ et al. observed endotoxin-induced activation of the extrinsic coagulation pathway in patients with acute appendicitis [4]. Other studies have identified inflammation as a risk factor for DVT [5]. Patients with acute appendicitis might be vulnerable to postoperative DVT/PE.

The incidence of DVT/PE differs depending on the diagnostic modality and criteria. In our center, the perioperative routine blood examination of patients who 
undergo surgeries for digestive diseases includes a Ddimer test. When the plasma D-dimer levels exceed approximately $10 \mu \mathrm{g} / \mathrm{ml}$, we obtain enhanced computed tomography (CT) scans (Fig. 1).

The reported symptomatic PEs constitute just the tip of the iceberg. An analysis of the underlying asymptomatic DVT/PE cases will help reveal the risk factors. Hence, we conducted this study to compare the postoperative incidence of DVT/PE among patients with acute appendicitis and other digestive diseases.

\section{Methods}

This study was approved by the ethical review board of the Shinshu Ueda Medical Center, and the need for informed consent from patients was waived. We retrospectively reviewed the medical records of patients who underwent digestive surgeries at Shinshu Ueda Medical Center from April 2018 to March 2019, attended by anesthesiologists (general anesthesia, neuraxial anesthesia, and local anesthesia). We excluded the following patients from the study: patients who already had PE or DVT on admission, and those who underwent a second operation during the hospital stay. We collected the following data: disease, operation method, age, sex, American Society of Anesthesiologist's Physical Status (ASA-PS), body mass index, operative time, D-dimer value (preoperatively, postoperatively within 24 hours, and on the following days), and DVT/PE diagnosis. Continuous data are presented as mean (25th to 75th percentiles).

\section{Diagnosis of DVT/PE}

DVT/PE was confirmed with enhanced CT scan when the plasma D-dimer value exceeded approximately $10 \mu \mathrm{g} / \mathrm{ml}$. Enhanced CT scanning was performed with a

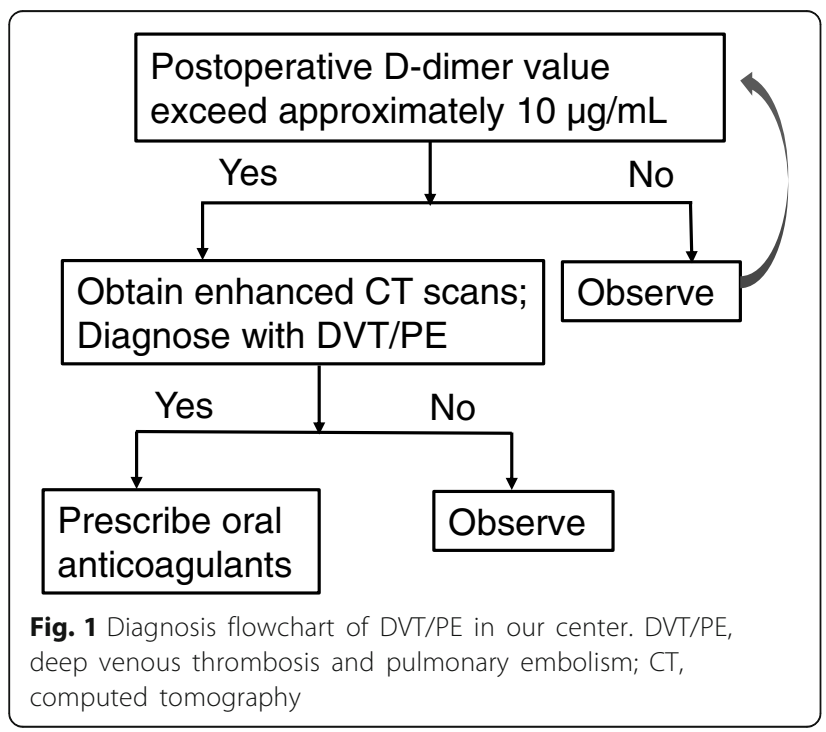

64-row multidetector scanner (Aquilion64; Canon Medical Systems Corporation, Ohtawara, Japan). A total non-ionic contrast material volume of 80 to $100 \mathrm{ml}$ (iodine concentration, $300-370 \mathrm{mg} / \mathrm{ml}$ ) was injected at the rate of 2.4 to $3.0 \mathrm{ml} / \mathrm{s}$ according to the patient's weight. For pulmonary embolism, the scanning was started at $25 \mathrm{~s}$ after the start of injection, and the whole lung area was assessed. For deep venous thrombosis, the scanning was started at $210 \mathrm{~s}$ after the start of injection and the region from the diaphragm to the toes was investigated. In both areas, data were acquired with $0.5 \mathrm{~mm}$ thickness scans, and reconstructed for $2.0 \mathrm{~mm}$-slice axial images, $5 \mathrm{~mm}$-slice sagittal images, and $5 \mathrm{~mm}$-slice coronal images. CT images were reviewed by a radiologist and the patient was accordingly diagnosed with DVT/PE. If a patient had any symptom of DVT/PE, we performed enhanced CT immediately, regardless of the D-dimer value. When the plasma $\mathrm{D}$-dimer value did not exceed approximately $10 \mu \mathrm{g} / \mathrm{ml}$ and there were no symptoms, we performed physical examination and ultrasonography, if necessary, for observation.

\section{Studies}

We reviewed the seven DVT/PE cases with acute appendicitis, including their symptoms, plasma D-dimer values, and $\mathrm{CT}$ findings.

We compared the incidence of DVT/PE between acute appendicitis and other disease categories. Then, we compared the background data (operative time and age) between patients with acute appendicitis and those with colorectal cancer, as asymptomatic DVT/PE incidence among colorectal cancer patients had been well studied $[6,7]$, and the number of operated cases are much higher in colorectal cancer than in other cancers. We thought DVT/PE incidence among colorectal cancer patients may provide a benchmark.

We further analyzed and compared the two categories of acute appendicitis, namely, complicated appendicitis and simple appendicitis. Categorization was made by intraoperative findings or postoperative pathological findings. We compared the incidence of DVT/PE, preoperative inflammatory biomarker (WBC, CRP, and Body temperature) levels, and plasma D-dimer values (preoperative and postoperatively within $24 \mathrm{~h}$ ) between the two categories.

\section{Statistical analysis}

The EZR (Saitama Medical Center, Jichi Medical University, Saitama, Japan) was used for statistical analyses. We compared the incidence of DVT/PE using the Fisher test with the Bonferroni post hoc test. We calculated the confidence interval of DVT/PE incidence with the Clopper-Pearson method. Continuous data were 
compared using the Mann-Whitney $U$ test. $P<0.05$ was considered statistically significant.

\section{Results}

After appendectomy, seven patients were diagnosed with DVT/PE (Table 1). Only one patient showed lower leg pain. Others had no remarkable clinical findings. We showed some of the CT images in Fig. 2. After diagnosis, they were referred to a cardiologist and treated with oral anticoagulants at least for three months [8].

We calculated the incidence of DVT/PE in each disease categories (Table 2). DVT/PE incidence in acute appendicitis patients was $9.1 \%$ (95\%CI 3.7-17.8). That incidence was significantly higher than that in the elective hernia patients. DVT/PE incidence in colorectal cancer patients was $7.2 \%(95 \% \mathrm{CI} 2.7-15.1)$. There were no statistically significant differences between the colorectal cancer patients and other disease categories.

Operative time and a patient's age are known risk factors for DVT/PE after a surgical operation. The operative time was significantly shorter in acute appendicitis patients than in colorectal cancer patients (68 [55-89] vs 184 [156-236] min; $P<0.001)$. The acute appendicitis patients were significantly younger than colorectal cancer patients $(40$ [14-58] vs 76 [68-83] years; $P<0.001)$.

Among the acute appendicitis group, six patients (6/30 20.0\%) with complicated appendicitis and one patient (1/47 2.1\%) with simple appendicitis had postoperative DVT/PE. Patients with complicated appendicitis had a higher risk of DVT/PE than those with simple appendicitis with an odds ratio of 11.5 (95\% CI 1.3-101.1). Among preoperative inflammatory biomarkers, CRP value was significantly higher in complicated appendicitis patients than in simple appendicitis patients (Table 3 ).

\section{Discussion}

In this retrospective study, DVT/PE occurred in seven and six patients after surgery for acute appendicitis and colorectal cancer. Furthermore, patients with complicated appendicitis showed a higher risk of DVT/PE than those with simple appendicitis.

The incidence of asymptomatic DVT/PE after colorectal surgery is reported in some literatures. Routine screening with Doppler ultrasonography revealed that the DVT incidence after colorectal surgery was 3.0\% [6]. Another study reported that DVT/PE incidence among laparoscopic colorectal surgery patients without anticoagulant prophylaxis was $5.1 \%$ using enhanced CT screening for all patients [7]. Higher incidence of DVT/ $\mathrm{PE}$ is reported in laparoscopic surgery for gastrointestinal cancer as $18.3 \%$ [9], and $24.3 \%$ in major abdominal surgery [10]. In this study, the incidence of DVT/PE after colorectal surgery was $7.2 \%$.

To our knowledge, DVT/PE incidence after surgery for acute appendicitis has not been reported yet. This neglect could be attributed to the absence of the three risk factors, cancer, long operative time, and older age, in the case of acute appendicitis. However, in our study, the $95 \%$ confidence interval for DVT/PE incidence in acute appendicitis patients was comparable to that in colorectal cancer patients (Table 2).

In further analysis, complicated appendicitis showed significantly higher incidence of DVT/PE than simple appendicitis. Inflammation was previously considered to be a risk factor of DVT/PE [5]. Patients with complicated appendicitis were reported to have higher plasma IL-6 level than those with simple appendicitis [11]. Elevated IL-6 might have induced DVT [12] in those patients. Further study is needed to confirm this theory.

Among DVT/PE cases after surgery for acute appendicitis, the $\mathrm{D}$-dimer values gradually increased with the passing day (Table 1). We do not know whether this reflected the resolution of the fibrinolysis suppression or a growing clot in the veins. If it is because of thrombosis progression a few days after the operation, enhancing the postoperative rehabilitation may be helpful for the prevention of DVT/PE.

Table 1 Seven cases of deep venous thrombosis and pulmonary embolism (DVT/PE) after appendectomy

\begin{tabular}{|c|c|c|c|c|c|c|c|c|c|}
\hline Case & Age (years) & Sex & $\begin{array}{l}\text { Operative } \\
\text { time (min) }\end{array}$ & Diagnosis day & Symptoms & Types of thrombosis & $\begin{array}{l}\text { Pre D-dimer } \\
(\mu \mathrm{g} / \mathrm{ml})\end{array}$ & $\begin{array}{l}\text { Post D-dimer } \\
(\mu \mathrm{g} / \mathrm{ml})\end{array}$ & $\begin{array}{l}\text { Diag D-dimer } \\
(\mu \mathrm{g} / \mathrm{ml})\end{array}$ \\
\hline Case 1 & 42 & Female & 83 & 2POD & None & PE & 1.1 & 6.4 & 9.0 \\
\hline Case 2 & 65 & Female & 94 & 3POD & None & PE & 0.7 & 6.1 & 10.5 \\
\hline Case 3 & 77 & Male & 80 & 3POD & None & PE & 6.0 & 8.1 & 23.3 \\
\hline Case 4 & 86 & Male & 129 & 6POD & None & Proximal DVT & 1.0 & 3.4 & 10.3 \\
\hline Case 5 & 47 & Female & 98 & 6POD & Lower leg pain & Distal DVT, PE & 1.2 & 5.2 & NA \\
\hline Case 6 & 82 & Female & 59 & 6POD & None & Distal DVT, PE & 3.5 & 6.3 & 48.0 \\
\hline Case 7 & 58 & Male & 74 & 5POD & None & Distal DVT, PE & 18.2 & 25.1 & 33.2 \\
\hline
\end{tabular}

Pre preoperative, Post postoperatively within $24 \mathrm{~h}$, Diag diagnosis day, POD postoperative day, PE pulmonary embolism, NA D-dimer was not studied that day Cases are arranged as per their order of occurrence 

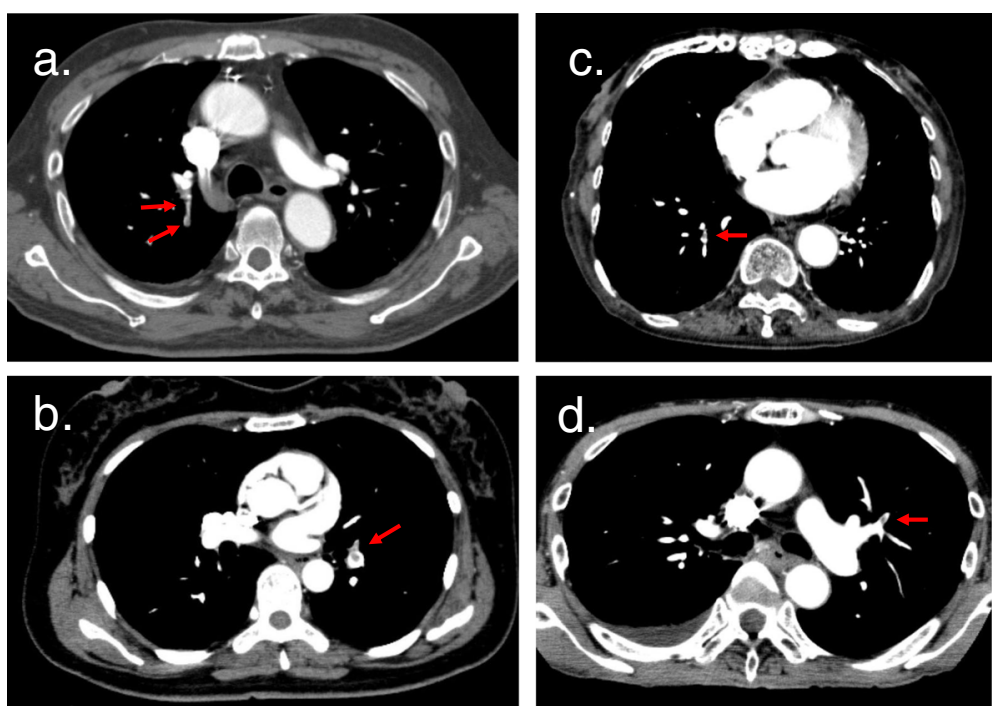

Fig. 2 Enhanced CT images of pulmonary embolism in four patients with acute appendicitis. Red arrows indicate thrombi. a On POD3, plasma D-dimer level was elevated to $23.3 \mathrm{\mu g} / \mathrm{ml}$. Enhanced CT revealed thrombus in right pulmonary artery. DVT was not found. b On POD6, the patient complained of right lower leg pain. Enhanced CT was performed without D-dimer test. Embolism in the left pulmonary artery and thrombi in the right popliteal vein and the right soleal vein were detected. c On POD6, plasma D-dimer level was elevated to $48.0 \mathrm{\mu g} / \mathrm{ml}$. Some embolus was detected on both sides of the peripheral pulmonary arteries. DVT was detected in the left soleal vein. $\mathbf{d}$ On POD5, plasma D-dimer level was elevated to $33.2 \mu \mathrm{g} / \mathrm{ml}$. Pulmonary embolism was detected in the upper right pulmonary artery. DVT was detected in the right popliteal vein. $\mathrm{CT}$, computed tomography; POD, postoperative day; DVT, deep venous thrombosis

Table 2 Incidence of perioperative deep venous thrombosis and pulmonary embolism (DVT/PE) after digestive surgery

\begin{tabular}{lll}
\hline Disease & $\begin{array}{l}\text { DVT or PE cases/total } \\
\text { number }(n=520)\end{array}$ & $\%(95 \% \mathrm{Cl})$ \\
\hline $\begin{array}{l}\text { Hepatic cancer, pancreatic } \\
\text { cancer }\end{array}$ & $5 / 22$ & $22.7(7.8-45.4)^{\mathrm{b}}$ \\
Colorectal perforation & $2 / 9$ & $22.2(2.8-60.0)$ \\
Acute appendicitis & $7 / 77$ & $9.1(3.7-17.8)^{\mathrm{a}}$ \\
Gastric cancer & $2 / 22$ & $9.1(1.1-29.2)$ \\
$\begin{array}{l}\text { Colorectal cancer } \\
\text { (elective surgery) }\end{array}$ & $6 / 83$ & $7.2(2.7-15.1)$ \\
Small bowel obstruction & $2 / 28$ & $7.1(0.9-23.5)$ \\
Acute cholecystitis & $2 / 41$ & $4.9(0.6-16.5)$ \\
$\begin{array}{l}\text { Strangulated hernia } \\
\text { (femoral or inguinal) }\end{array}$ & $0 / 16$ & $0(0-20.6)$ \\
Gastrointestinal perforation & $0 / 7$ & $0(0-41.0)$ \\
Hernia (elective surgery; & $0 / 133$ & $0(0-2.7)^{\mathrm{a}, \mathrm{b}}$ \\
femoral or inguinal) & & $0(0-7.9)$ \\
Gallstone & $0 / 45$ & $5.4(0.7-18.2)$ \\
\hline Others & $2 / 37$ &
\end{tabular}

DVT deep venous thrombosis, $P E$ pulmonary embolism, $\mathrm{Cl}$ confidence interval Sixteen patients were excluded from the study (patients who already had PE or DVT on admission, or those who underwent a second operation during the hospital stay)

Perforated colorectal cancer cases were included in "colorectal perforation" ${ }^{a}$ Acute appendicitis vs hernia (elective surgery), $p=0.049$

${ }^{\mathrm{b}}$ Hepatic cancer, pancreatic cancer vs hernia (elective surgery), $p=0.003$ No statistically significant differences were seen among other categories (Fisher test, Bonferroni post hoc test)

95\% confidence intervals were calculated with the Clopper-Pearson method
The limitations of this study were that this was a single-center study, technical errors might have occurred while drawing blood (slow drawing causes coagulation cascade in the needle), the timing of blood sampling was not strictly determined, and our attending physicians used a high D-dimer cutoff value of approximately $10 \mu \mathrm{g} / \mathrm{ml}$ for ordering enhanced CT based on their clinical experiences, instead of conventionally proposed $0.5 \mu \mathrm{g} / \mathrm{ml}$ [13]. Therefore, some patients with DVT/PE might not have been diagnosed.

Future studies should evaluate other non-malignant inflammatory diseases as risk factors for DVT/PE and

Table 3 Comparison of the inflammatory biomarkers and plasma D-dimer levels between complicated appendicitis and simple appendicitis

\begin{tabular}{llll}
\hline Variable & $\begin{array}{l}\text { Complicated } \\
(n=30)\end{array}$ & Simple $(n=47)$ & $P$ value \\
\hline Temperature $\left({ }^{\circ} \mathrm{C}\right)$ & $37.2(36.7-38.3)$ & $37.1(36.7-37.7)$ & 0.32 \\
WBC $\left(10^{2} / \mu \mathrm{l}\right)$ & $12,700(10,300-15,650)$ & 12,600 & 0.59 \\
& & $(9500-14,500)$ & \\
CRP $(\mathrm{mg} / \mathrm{dl})$ & $9.4(4.0-18.4)$ & $1.0(0.4-2.4)$ & $<0.001^{*}$ \\
Pre D-dimer $(\mu \mathrm{g} / \mathrm{ml})$ & $1.15(0.58-2.65)$ & $0.40(0.13-0.70)$ & $<0.001^{*}$ \\
Post D-dimer $(\mu \mathrm{g} / \mathrm{ml})$ & $3.45(1.75-6.10)$ & $0.50(0.30-1.30)$ & $<0.001^{*}$
\end{tabular}

WBC white blood cell count, CRP C reactive protein, Pre D-dimer plasma Ddimer level examined preoperatively, Post $\mathrm{D}$-dimer plasma D-dimer level examined postoperatively within $24 \mathrm{~h}$

Continuous data are presented as median (25th to 75 th percentile)

$P$ values were calculated using the Mann-Whitney $U$ test ${ }^{*} P<0.05$ 
explore their associated thromboses and hemostasis mechanisms. In addition, the adequate perioperative Ddimer cutoff value for digestive surgeries should be studied.

\section{Conclusions}

In summary, our data demonstrated that complicated appendicitis could be a risk factor for postsurgical DVT/ $\mathrm{PE}$. Among DVT/PE cases after surgery for acute appendicitis, the D-dimer values increased with the passing day. Thus, caution must be exercised during the perioperative period for preventing DVT/PE.

\section{Abbreviations}

DVT/PE: Deep venous thrombosis and pulmonary embolism; CT: Computed tomography; ASA-PS: American Society of Anesthesiologist's Physical Status; POD: Postoperative days

\section{Acknowledgements}

We would like to thank Editage (www.editage.com) for English language editing.

\section{Authors' contributions}

$\mathrm{OH}$ designed the study, analyzed the data, and wrote the first draft of the manuscript. OE, IM, and MN advised on data interpretation and critically revised the manuscript. All authors contributed and approved the final manuscript.

\section{Funding}

No funding was provided

\section{Availability of data and materials}

The datasets generated and/or analyzed during the current study are available from the corresponding author on reasonable request.

\section{Ethics approval and consent to participate}

This study was approved by the ethical review board of the Shinshu Ueda Medical Center on 25 April 2019 (approval number 31-1), and the need for informed consent from patients was waived.

\section{Consent for publication}

Not applicable

\section{Competing interests}

The authors declare that they have no competing interests.

Received: 14 January 2020 Accepted: 9 March 2020

Published online: 16 March 2020

\section{References}

1. Ay C, Pabinger I, Cohen AT. Cancer-associated venous thromboembolism: burden, mechanisms, and management. Thromb Haemost. 2017;117(2):219-30.

2. Walker AJ, Card TR, West J, Crooks C, Grainge MJ. Incidence of venous thromboembolism in patients with cancer-a cohort study using linked United Kingdom databases. Eur J Cancer. 2013:49(6):1404-13.

3. Sakon M, Kakkar AK, Ikeda M, Sekimoto M, Nakamori S, Yano M, Monden M. Current status of pulmonary embolism in general surgery in Japan. Surg Today. 2004;34(10):805-10.

4. Li J, Liu Y, Yin W, Zhang C, Huang J, Liao C, Nie L, Zhou Y, Xiao P. Alterations of the preoperative coagulation profile in patients with acute appendicitis. Clin Chem Lab Med. 2011;49(8):1333-9.

5. Branchford BR, Carpenter SL. The role of inflammation in venous thromboembolism. Front Pediatr. 2018. https://doi.org/10.3389/fped.2018.00142

6. Lee E, Kang SB, Choi SI, Chun EJ, Kim MJ, Kim DW, Oh HK, Ihn MH, Kim JW, Bang SM, Lee JO, Kim YJ, Kim JH, Lee JS, Lee KW. Prospective study on the incidence of postoperative venous thromboembolism in Korean patients with colorectal cancer. Cancer Res Treat. 2016;48(3):978-89.
7. Hata T, Yasui M, Ikeda M, Miyake M, Ide Y, Okuyama M, Ikenaga M, Kitani K, Morita S, Matsuda C, Mizushima T, Yamamoto H, Murata K, Sekimoto M, Nezu R, Mori M, Doki Y. Efficacy and safety of anticoagulant prophylaxis for prevention of postoperative venous thromboembolism in Japanese patients undergoing laparoscopic colorectal cancer surgery. Ann Gastroenterol Surg. 2019:3(5):568-75.

8. Di Nisio M, van Es N, Büller HR. Deep vein thrombosis and pulmonary embolism. Lancet. 2016;388(10063):3060-73.

9. Kimura Y, Oki E, Ando K, Saeki H, Kusumoto T, Maehara Y. Incidence of venous thromboembolism following laparoscopic surgery for gastrointestinal caner: a single-center, prospective cohort study. World J Surg. 2016; 40(2):309-14.

10. Sakon M, Maehara $Y$, Yoshikawa $H$, Akaza $H$. Incidence of venous thromboembolism following major abdominal surgery: a multi-center, prospective epidemiological study in Japan. J Thromb Haemost. 2006; 4(3):581-6.

11. Rivera-Chavez FA, Wheeler H, Lindberg G, Munford RS, O'Keefe GE. Regional and systemic cytokine responses to acute inflammation of the vermiform appendix. Ann Surg. 2003;237(3):408-16.

12. Zhang $Y$, Zhang Z, Wei R, Miao X, Sun S, Liang G, Chu C, Zhao L, Zhu X Guo Q, Wang B, Li X. IL (interleukin)-6 contributes to deep vein thrombosis and is negatively regulated by miR-338-5p. Arterioscler Thromb Vasc Biol. 2020;40(2):323-34

13. Goldhaber SZ, Bounameaux H. Pulmonary embolism and deep vein thrombosis. Lancet. 2012;379(9828):1835-46.

\section{Publisher's Note}

Springer Nature remains neutral with regard to jurisdictional claims in published maps and institutional affiliations.

\section{Submit your manuscript to a SpringerOpen ${ }^{\circ}$ journal and benefit from:}

- Convenient online submission

- Rigorous peer review

- Open access: articles freely available online

- High visibility within the field

Retaining the copyright to your article

Submit your next manuscript at $>$ springeropen.com 